\title{
"Smoke on the beach": on the use of economic vs behavioral policies to reduce environmental pollution by cigarette littering
}

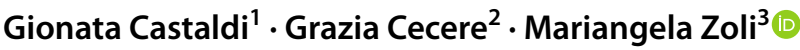

Received: 30 May 2020 / Accepted: 31 October 2020 / Published online: 16 November 2020

(c) The Author(s) 2020

\begin{abstract}
Cigarette filters, the most commonly littered item worldwide, are one of the main sources of marine pollution. However, reducing cigarette littering is a serious challenge for policy makers and environmental authorities: traditional instruments like bans and fines are generally ineffective. In this article, we evaluate the impact of two interventions aimed at reducing smokers' littering in public areas, like beaches. We run a field experiment at eight beach resorts in the north east coast of Italy. Resorts were randomly assigned to three groups: in the first, we introduced portable ashtrays to test whether smokers respond to the lower effort costs (time plus inconvenience) by disposing of litter properly. In the second set, we added a social cue. The third group of resorts was used as a control with no intervention. Results suggest that reducing the private costs of a proper disposal through mobile ashtrays significantly affects littering, leading to a reduction of $10-12 \%$ in the number of cigarette filters dropped in the sand compared to beaches with no ashtrays. Reinforcing this measure with social prompts does not significantly increase the impact driven by the introduction of mobile ashtrays.
\end{abstract}

Keywords Cigarette butt litter · Marine pollution · Effort cost of disposal $\cdot$ Social norm $\cdot$ Small-scale field experiment

JEL Classification C93 · Q50 - Q53

Mariangela Zoli

zoli@uniroma2.it

1 Ministry of Economy and Finance, Rome, Italy

2 Institut Mines Telecom, Business School, LITEM, Paris, France

3 Department of Economics and Finance (DEF), University of Rome Tor Vergata, CEIS and SEEDS, Via Columbia, 2, 00133 Rome, Italy 


\section{Introduction}

Cigarette filters are the most littered item worldwide; they are ubiquitous on streets, sidewalks, parks and other open areas. It is estimated that roughly 4.5 of the 6 trillion cigarettes smoked across the world every year are discarded into the environment (Novotny and Slaughter 2014). In addition to aesthetic concerns, cigarette littering poses a serious threat to the environment and human health, due to both their plastic elements and their toxic and carcinogen components. Plastic components that make up the filter, like cellulose acetate, eventually can be broken down into smaller pieces, but they accumulate in the environment due to their slow degradation rate (Bonanomi et al. 2015). According to some studies, their source material never disappears (Novotny et al. 2009). Chemicals and hazardous components contained in cigarette ends, such as nicotine, heavy metals, benzene and volatile organic compounds, may leach out, contaminating soils and aquatic environments (Lombardi et al. 2009; Slaughter et al. 2011; Green et al. 2014, 2019).

Filters littered in beaches represent a serious risk to marine ecosystems. They may reach the sea where they contribute to the release and accumulation of pollutants and create acute harm to marine organisms (Moerman and Potts 2011; Wright et al. 2015). Filters have a negative impact on marine wildlife: ingestion and entanglement of smoking debris by seabirds, turtles, mammals and fishes have been widely documented by the literature (Derraik 2002; Wilcox et al. 2016). The ingestion of microplastics released by filters transfers pollutants to animals' bodies, causing various health impacts for them (Rochman et al. 2013) but also for humans, as microplastics have been found in marine organisms destined for human consumption (Van Cauwenberghe and Janssen 2014).

Due to the small size of filters, monitoring and cleaning operations are costly and often ineffective. Differently from other types of littering, traditional policy instruments, mainly based on bans and monetary sanctions, have been proved to have only a modest impact in reducing the number of discarded butts. Tackling cigarette littering is then a serious challenge for policy makers and environmental authorities.

In order to understand the drivers of cigarette littering and to suggest potential policy strategies, we run a field experiment. The theoretical framework of our experimental design can be summarized as follows.

In the economic literature, littering is a classic externality arising from the divergence between private and social costs. When taking waste home or walking in search of an ashtray entails private costs (time plus effort) which exceed the cost of throwing waste on the ground, agents will choose to litter (Dobbs 1991), disregarding the large social costs (in terms of health, environmental, and aesthetic impact) caused by the accumulation of litter. As a result, the extent of litter is distorted towards the less desirable alternative from a social perspective (Choe and Fraser 1998; Kinnaman and Fullerton 1999; Ferrara 2008, among others). In this theoretical set-up, changing the relative cost of different waste disposal options, by increasing private costs of littering and/or making non-littering more convenient, should lead to reduced litter. 
In the case of cigarette butt disposal, however, changing individual behavior raises challenges different from other types of littering, since cigarette butts are habitually and even unconsciously flicked away after smoking. This type of littering may then be a case where social incentives, such as social sanctions and norms, can be more powerful than economic incentives, as suggested by a recent behavioral and psychological literature.

Drawing on these considerations, in this article we study the causal effect of two interventions aimed at lowering cigarette end littering. The first follows a "more conventional" economic approach aiming at reducing the effort costs of proper cigarette butt disposal. The second attempts to alter the attitude to littering through increasing individual awareness of the social benefits of litter reduction.

We carried out a small-scale field experiment at eight beach resorts in the Emilia-Romagna region, on the northeast coast of Italy, in the period June-August 2015. Overall, more than 56,000 visitors of the beaches have been involved by the experiment. The northeast Adriatic cost of Italy is a particularly interesting environment where running the experiment. These beaches are vulnerable to litter accumulation from land sources, due to waste discharged by rivers, and population concentration along the coasts, especially in the summer season, when recreational marine activities multiply the production of litter (Munari et al. 2016).

We sorted beach resorts randomly into three groups. In the first group, we provided free portable ashtrays. These ashtrays, which beach visitors could take freely and use near where they were sunbathing, reduced the hassle of proper disposal by avoiding the need to walk to a central trash bin to dispose of the cigarette butt. For the second group of beaches we provided free portable ashtrays but also added signboards with messages explicitly encouraging the use of ashtrays to keep the beach clean. The aim was to activate a social injunctive norm. The third group of beaches was the control group, with no intervention.

Our results suggest a beneficial effect of free portable ashtrays: in treated beaches, we had a statistically significant reduction in butts dropped in the sand, compared to untreated beaches. Specifically, portable ashtrays (with and without the message) caused a reduction of cigarette butts in the sand (per visitor and per total number of cigarettes smoked) in the range 10-12\% compared to beaches with no ashtrays, according to different model specifications. The slightly different effect obtained when the presence of ashtrays was reinforced with signboards turned out not to be statistically significant compared to results obtained on beaches with only portable ashtrays (reductions range from 7 to 13\%). Our experiment then suggests that, in the case of smokers' littering, the adoption of an economic incentive, which reduces the effort cost of a proper disposal, can be effective in tackling improper dumping.

Our findings provide policy recommendations for an effective strategy towards cigarette littering reduction. It is worth to note that, after our experiment, in summer 2019, the local authority of the province where participating beach resorts are located promulgated a new ordinance (Ordinanza TL n.1140, 11/07/2019) along the lines suggested by our findings. Specifically, the ordinance mandates that, "in order to avoid waste dumping, beach visitors are required to have a proper (disposable or 
reusable) receptacle for filters and other smoking related residues, to reduce the risk of creating environmental damages and hazards to people' safety". ${ }^{\prime}$

This policy suggestion is also coherent with the EU Marine Strategy Framework Directive (2008/56/EC), which establishes a framework for Member States to take action in order to achieve Good Environmental Status (GES) for the marine environment. Marine litter, defined as any persistent, manufactured or processed solid material discarded, disposed of or abandoned in the marine and coastal environment (UNEP 2009), is one of the eleven Descriptors of the Strategy.

Even though marine litter is a serious problem in the Mediterranean area, due to the peculiar characteristics of its ecosystems, only very few studies have explored the environmental consequences of the problem so far. By looking at Italy, some studies show that both seabed and sandy shore litter is a serious threat to the environment and biotic marine communities (Strafella et al. 2019; Poeta et al. 2014). Munari et al. (2016), in a study conducted in five beaches in the Northeast coast of Italy, find that the great majority of litter $(81.1 \%)$ is made of plastic items, within which cigarette butts accounts for the highest percentage $(22.9 \%)$.

Our research contributes to both the economic and the psychological literatures investigating the determinants of littering behavior. Our main innovation relative to previous studies is the random assignment of the treatments. Indeed, to the best of our knowledge, ours is the first field experiment where the effects of increasing the convenience of proper waste disposal and adding a social prompt are investigated through randomized interventions. The random assignment and the chosen experimental setting reduce the risk of having spurious correlation between littering and the presence of ashtrays. The beach resorts in our field experiment have similar characteristics in terms of the pre-treatment availability of ashtrays and generic bins. This allows us to exclude the possibility that the availability of ashtrays at a particular resort could have influenced ex-ante the choice of whether to visit that resort. Finally, the randomization check ensures that beaches in different treatments are balanced in terms of background characteristics. ${ }^{2}$

The remainder of the paper is structured as follows. Section 2 reviews the relevant literature to frame conceptually the environmental and social problems related

\footnotetext{
${ }^{1}$ English translation for the second article of the ordinance. In Italian, the article states that "essendo in ogni modo vietato l'abbandono di rifiuti, è necessario munirsi di un idoneo contenitore riutilizzabile oppure "usa e getta" utile per la raccolta di mozziconi o altri rifiuti di prodotti da fumo, al fine di evitare danni all'ambiente, nonché possibili pericoli per l'incolumità e la sicurezza delle persone”.

2 In other words, the random assignment of treatments reduces the risk of having a spurious correlation between littering and the availability of ashtrays due to the possibility that resorts' unobserved characteristics are causing easy availability of ashtrays and of individuals inclined to dispose of their butts properly. Another, possibly less plausible, source of spurious correlation might be that people who dislike littering choose to patronize locations with an abundant availability of ashtrays in order to reduce the effort cost of avoiding littering. This is unlikely in the specific environment considered in this study: we preliminary checked that beach resorts in our field experiment provided quite similar services, also in terms of the availability of ashtrays and generic bins. People tend to choose which resort to patronize according to a variety of reasons, from the type of restaurant to the company available. Smoking is allowed and it is relatively easy and effortless to hide cigarette butts in the sand; it seems unlikely that the availability of ashtrays at a particular resort should influence the choice of whether to visit that resort.
} 
to cigarette butt littering, and the potential applicability of economic and behavioral instruments. Section 3 provides details of the experimental design and its implementation. Section 4 describes the dataset and introduces the econometric strategy, while Sect. 5 reports the empirical findings and some robustness checks. Section 6 concludes.

\section{Cigarette littering}

Cigarette filters are the most common form of litter in the world (Curtis et al. 2014; Novotny and Slaughter 2014; Moerman and Potts, 2011). Filters that end up on beaches are a serious source of concern for marine pollution. Ocean Conservancy, a non-profit environmental advocacy group in the US that organizes the world's largest annual coastal cleanup, reports cigarette butts as the most collected item, with more than 5,716,000 filters collected in the 2018 campaign (Ocean Conservancy 2019). ${ }^{3}$

Contrary to the health consequences of tobacco use, the damage caused by filters is only just beginning to be investigated. ${ }^{4}$ According to recent studies, it is indisputable that the toxic, irritant, and carcinogenic content of filters has the potential to create serious damages to human health and the environment. Novotny et al. (2011) provide a summary of reports of ingestion from the relevant literature, showing that accidental ingestion of cigarette butts is frequent among children, especially very young children, who can choke or be poisoned by toxic substances in the filter. Some reports show severe toxicity effects such as respiratory problems, arrhythmia, and convulsions (see CDC 1997; Malizia et al. 1983, among others).

Ingestion and entanglement episodes are widely documented for marine wildlife: every year, hundreds of thousands of fish, sea turtles, marine mammals, and more than a million seabirds die from ingesting marine debris, including cigarette butts ${ }^{5}$. Wilcox et al. (2016) collect information from experts on the threat of entanglement, ingestion and chemical contamination for seabirds, sea turtles and marine mammals. The plastic components and the toxic metal contents of cigarette butts introduce critical risks also to human health, when polluted marine organisms enter the food chain and are used for human consumption (Van Cauwenberghe and Janssen 2014; Rochman et al. 2015; Dobaradaran et al. 2018).

\footnotetext{
3 Several sources confirm that cigarette butts dominate among the items littered on coastlines all around the world. Together with the reports by Ocean Conservancy (https://oceanconservancy.org/trash-freeseas/international-coastal-cleanup/annual-data-release/), see also the Great Canadian Shoreline Report (2018) at https://www.shorelinecleanup.ca/annual-report or the annual reports by Legambiente for Italian beaches (https://www.legambiente.it/indagine-beach-litter/). Last accessed 20/03/2020.

${ }^{4}$ Studies which provide a quantitative analysis of the negative impact of cigarette butts are complicated because data on their chemical components are not exhaustive, and depend on several factors, such as the type of additives used by the tobacco industries, tobacco residues, etc. (ENEA 2010).

5 https://tobaccofreelife.org/resources/marine-life-cigarettes-pollution/; http://www.seeturtles.org/oceanplastic/ - last accessed 20/03/2020).
} 
Given their small size, collecting cigarette ends is both difficult and costly since they are often trapped in cracks in sidewalks, in manholes, bushes, and of course beaches.$^{6}$ In natural environments, such as beaches and parks, mechanical cleanup is impossible and manual operations are often necessary to remove filters from the sand and vegetation. Besides their costs, cleaning operations are not completely effective. Loizidou et al. (2018), for instance, report results from cleanups organized by the responsible authorities on nine Blue Flag beaches in Cyprus, showing that efforts are quite successful at collecting larger pieces of marine litter, but that small pieces, such as cigarette butts, remain on the beach.

Growing concerns over the health and environmental impact of cigarette related litter have led governments to undertake a variety of policy initiatives, including enforcing anti-littering laws, the introduction of fines and/or smoking bans in public areas, and waste fees (Barnes 2011). Unlike the case of other littered items, however, traditional policy instruments have proved to have only a modest impact in reducing cigarette butt littering. Fines, for instance, are often impractical, due to the difficulty of monitoring and the related enforcement costs, ${ }^{7}$ while schemes such as depositrefunds cannot apply to cigarette butts due to the low value of their components, aesthetics reasons (smell), toxicity of the chemicals they release, and the special treatment required to handle, dispose of, and transport them (Curtis et al. 2014).

While the impact of governments' "negative penalty structures" which discourage littering by increasing its cost seems to be modest, the provision of "positive" incentives which reduce the effort costs of a proper disposal might be more effective $^{8}$ (Bell et al. 2017). A common finding in the psychological literature on littering behavior is that the presence and attractiveness of receptacles can reduce littering rates (Finnie, 1973; Geller et al. 1979; O'Neill et al. 1980). Exceptions in this respect are Burgess et al. (1971), which shows that doubling the number of trash cans does not have any effect on litter in theaters, and Roales-Nieto (1988), which shows that increasing the number of trash receptacles (with or without publicity campaigns) causes only a minimal decrease in litter. By distinguishing between cigarette and non-cigarette waste, Sibley and Liu (2003) collect observational data in a

\footnotetext{
${ }^{6}$ Schneider et al. (2011) report that the total public costs involved in removing tobacco related products range from some US\$0.5 million to US\$6 million depending on the city size. In their study, they estimate total cigarette related waste costs to S. Francisco as around US\$5.6 million.

7 Fines discourage littering by increasing the relative cost of bad disposal, providing, at the same time, a source of revenue for local communities, which could adopt it to finance, for instance, clean-up costs. This is clearly a positive feature of this instrument, which, however, should be balanced with the administrative costs of implementing the related monitoring and enforcement system. It may be difficult and costly to monitor and punish littering behaviors, especially in the case of small littered items. Accordingly, the perceived low probability of being caught, together with the low probability of being subject to a penalty, if caught, can explain why fines provide a weak stimulus to change behavior.

${ }^{8}$ In this respect, our work relates to the recent literature which explores the relevance of the opportunity cost of time on household recycling decisions (Halvorsen 2008) and the role of positive incentives to reduce recycling inconvenience (Ong and Sovacool 2012; Bell et al. 2017). Bell et al. (2017), for instance, highlight that governments' effort has evolved from imposing costs on households that do not recycle to mechanisms that increase households' participation by reducing the time and effort needed to recycle, i.e. increasing the number and convenience of drop-off centers or introducing single-stream recycling.
} 
university quad for two interventions aimed at reducing active and passive littering. ${ }^{9}$ They find that, while posting daily feedback on the percentage of men and women who have littered is only slightly effective for reducing cigarette litter, the introduction of ashtrays has a relevant impact, although the major increase is in the active disposal of butts since passive disposal remains low across different conditions. These findings suggest that ashtrays help individuals to overcome one of the major obstacles to proper disposal, namely the difficulty of finding a suitable bin. Surveys conducted on smokers reveal that $42 \%$ of them find it difficult to dispose of cigarette butts without littering due to problems related to finding a proper bin and the potential risk of fire from placing butts in an ordinary bin (Mcgregor Marketing 1998).

Other studies argue that the density of ashtrays can be a relevant predictor of littering behavior. ${ }^{10}$ Schultz et al. (2013), for instance, find that both the presence and number of ashtrays are significant predictors of littering behavior. In particular, by adopting an observational protocol in several different places in the US, they find that cigarette end littering rates are lower if the number of ashtrays available in the monitored area is larger, and that littering increases significantly with the distance to the receptacle at the time of disposing. These findings are consistent with the idea that butt littering can be affected by increasing the convenience of proper disposal, and provide theoretical support for our treatments.

Difficulties in reducing cigarette waste littering also emerge due to the complex nature of smokers' behavior regarding cigarette end disposal. Indeed, tossing ends away is an unconscious and largely "ignored behavior" among smokers, an action they are not aware of, and which is part of the smoking ritual (Novotny et al. 2009). Lack of attention and limited concentration on the specific action they perform, together with the idea that end littering is so widespread that it can be considered to be almost acceptable (Cope et al. 1993; Healton et al. 2011; Smith and Novotny 2011, Rath et al. 2012) may be factors to explain improper butt disposal behavior. Results in Rath et al. (2012) show that individuals "who do not believe or are not sure whether cigarette butts are litter" are over 3.5 times as likely to report having thrown their cigarette butts on the ground or out of a car window at some point during their lifetime.

In cases where personal motivations and values may be relevant, behavioral economics suggests complementing traditional policy instruments with new forms of intervention aimed at subtly altering individual choices and helping people to pursue their own interests (Chetty 2015). In the littering context, the observation that individuals care about what others are doing and how they may be judged by others has led some authors to explore the use of social norms. Cialdini et al. (1990) argue that both descriptive norms, defined as "what most others do", and injunctive

\footnotetext{
9 The difference between active and passive littering is given by the latency between the placement of litter and the vacation of the area.

10 An exception is Cope et al. (1993) which reports on two different experiments conducted at a university campus in North Carolina, to evaluate the impact of both an increased number of ashtrays and the introduction of decorated ashtrays. Their findings suggest that the presence of ashtrays decreases cigarette litter compared to the baseline scenario without ashtrays, but the density of receptacles does not significantly affect litter.
} 
norms, "what is socially accepted within a culture", affect littering behavior, but that it is necessary to distinguish between them, because both types of norms can coexist and push behavior in either direction. In their experiments, the authors observe individual littering behavior after a change in the amount of litter in the environment, and note that people tend to discard less in a clean environment than in a littered environment. ${ }^{11}$ Kallgren et al. (2000) asked colleagues to exhibit clean behavior (by picking up a crumpled fast-food bag from the ground in a parking lot) to check the reactions of other people. Their findings confirm that an unobtrusive intervention such as "setting a good example" is effective for reducing littering. In order to compare the impact of different types of norms, De Kort et al. (2008) attached to trashcans signboards with different messages, to show that messages activating personal and injunctive norms reduced litter more compared to messages related to descriptive norms.

Our experimental design is inspired by the above reviewed literature. Based on previous findings, we can formulate the following research hypotheses with respect to the treatment effects:

Hypothesis 1 The availability of portable ashtrays for smokers, who may decide freely to use them or not, decreases the number of cigarette butts on the beach.

Hypothesis 2 Providing a social cue, which explicitly invites people to keep the beach clean, strengthens the effect of free portable ashtrays.

\section{Experimental design}

We carried out a field experiment at eight ${ }^{12}$ beach resorts in Emilia Romagna, in northeastern Italy (see map in Fig. 2 in the Appendix for the location of the beach resorts).

The cooperation of resorts' managers and workers who clean the beaches was indispensable to run the experiment, as it required the separate collection of butts found in the sand and in ashtrays/generic bins. This clearly involved an extra effort for beach workers, in the period of the highest customers' attendance. Among resorts which agreed to participate in the experiment and to help us, we selected those beach resorts that had similar characteristics, in terms of infrastructures and

\footnotetext{
11 More recently, Dur and Vollaard (2015) show that public cleaning policies may stimulate both positive behaviors of litter reduction and free-riding actions. Through a natural field experiment, the authors find that reducing the frequency of cleaning services at garbage container locations has the main effect of increasing the tendency to litter (by 75\%). Nevertheless, they also find evidence that some people start to clean up after themselves, as suggested by the increase in the number of appointments for pick-up of discarded household items.

12 While the small number of participating resorts defines the experiment as a case-study, the use of small-scale field experiment is increasingly used to investigate environmental behaviors. Kurz (2018), for instance, assesses the impact of a nudge in increasing the share of vegetarian lunches sold at two university restaurants.
} 
cleanliness of the beach, and that were not neighboring, to avoid contamination and to guarantee the absence of spillover effects. ${ }^{13}$

Furthermore, we checked that resorts had not adopted any kind of portable receptacles for smokers, before the introduction of our treatments.

The resorts were split randomly into three different groups, labelled: ASHTRAY, ASHTRAY PLUS MESSAGE, and CONTROL GROUP. As argued in the Introduction, the randomization process helps to control for potential correlation between the unobserved characteristics of the beach resorts and the attitudes of the people visiting them. By assigning treatments randomly across beach resorts, we can identify the causal effect of intervention on the reduction of cigarette litter. The between-subject design avoids most of the confounding effects that might arise in a within-subject $\operatorname{design}^{14}$ (Charness et al. 2012). Since in this experiment the subjects, the visitors to the resorts, are unaware of participating, we feel entitled to draw causal estimates from our treatment effects (Levitt and List 2009).

The experiment lasted 53 days, from the end of June to mid-August 2015 . $^{15}$ This is the peak holiday season: on average, $80 \%$ of the annual visits to these beaches occur in this period. The total number of people visiting the beach resorts during the period was about 56,000 individuals. The characteristics of the holiday season in the region and the pattern of visitors' attendance limited the timespan of the experiment and made a possible pre-treatment period unlikely to be meaningful. The pre-season period is fundamentally different: tourists are different (more walkers, fewer sunbathers), restaurants are closed, and the owners do not clean the beach every day, as they do in July and August.

The detailed experimental design is as follows. The AsHTRAYs treatment involved three beach resorts. In these resorts, portable ashtrays were made freely available: they could be taken from baskets located in very visible points near the boardwalk leading to the beach ${ }^{16}$ (see Fig. 3 in the Appendix) allowing people to take one before they reached the beach to sit down for the day. In this group of resorts, the availability of ashtrays was not accompanied by any encouragement.

The ASHTRAYS PLUS MESSAGE treatment involved three other beach resorts where the provision of free portable ashtrays was accompanied by posters near the baskets containing the ashtrays and in other visible locations such as near the entrance to the

\footnotetext{
13 Operators in the resorts are used to cleaning the beach every evening, to guarantee the sand clean for the customers of the next day. Cleaning operations are usually performed in the resorts, independently of our experiment; this means that we can exclude that the treatments increased the cleanliness of beaches and that the number of customers was consequently affected. In the following, we check the balancing of the number of customers in the three groups of beaches (see Table 3).

14 Potentially confounding effects due to learning may arise due to the nature of attendance in these beach resorts, where customers tend to spend quite long periods (visiting for at least 15 days), and weekends visitors generally patronize the same resort.

15 This corresponds to around 42 observations for each resort. The missing data are due mainly to adverse weather conditions, causing both customers' non-attendance and suspension of the waste collection process from the sand since wet sand constitutes a major obstacle to the collection of litter.

16 The portable receptacles were constructed of recycled polypropylene which in turn is $100 \%$ recyclable. Each portable receptacle cost 0.36 euros and can be re-used several times before being recycled with plastic materials.
} 
resort and by the coffee shop. Posters displayed the anti-litter message in a slightly jocular Italian sentence that translates as "One more thought for your beach, one less cigarette filter in your sand"17 (Fig. 4). We chose the text of the message to be consistent with suggestions in the psychology literature which highlights the importance of well-crafted messages, especially in environmental contexts, and underlines the need to account for what the majority of people consider to be desirable (Cialdini 2003). We made the specific decision to employ a positively phrased message since this is considered to be more effective than a negatively phrased prompt ${ }^{18}$ (de Kort et al. 2008; Hansmann et al. 2009).

Two resorts were assigned to the CONTROL group and did not receive any treatment.

To evaluate the impact of the treatments, we counted the number of filters left in the sand, and the filters disposed of by smokers in portable ashtrays and in other trash bins placed around the beach, i.e. in generic bins, to capture the contents of ashtrays that people had emptied. ${ }^{19}$

Resort managers and the researchers monitored the collection of cigarette butts which were gathered and counted by the authors (Fig. 5). It should be noted that our treatments did not stop smokers from tossing filters into the sand: they were not obliged either to take or to use the ashtrays. However, at the same time, the availability of portable ashtrays and the elicitation of the social norm might have stimulated more appropriate disposal behavior.

\section{Empirical model}

To test our research hypotheses, in most of our empirical analysis we examine the effect of the treatments on the ratio of the number of cigarette ends collected from the sand and the number of customers (Litter), according to the following econometric specification ${ }^{20}$ :

$$
\begin{aligned}
\text { Litter }_{i t}= & \alpha+\beta_{1} \text { ashtrays }+\beta_{2} \text { ashtrays plus message } \\
& +\gamma_{1} \text { DailyFE }_{t}+\gamma_{2} \text { DayOfWeekFE }_{t}+\delta X_{i t}+\theta Z_{i} \\
& +\mu \text { Weather }_{t}+\varepsilon_{i t} ;
\end{aligned}
$$

\footnotetext{
17 It was not necessary to translate the message into English because almost all beach visitors to our resorts are Italian.

18 Reich and Robertson (1979) perform three experiments to show that anti-littering messages may have different effects in terms of the social pressure they impose. Their findings suggest that the provision of positive messages (internal pressure) reduce litter more, compared to explicit commands prohibiting litter (external pressure). Analogously, in Reiter and Samuel (1980), a control condition is compared with a threatening message ("Littering is unlawful and subject to a $\$ 10$ fine") and with a cooperative prompt ("Pitch in!"). They find that the threatening message reduces litter with respect to the control setting but the cooperative message achieves the best results.

19 It is worth to explain that the separated collection and counting of butts were done in all resorts of the three groups, to compare the average effect of the treatments compared to the control.

20 The equation is estimated by using the least squares dummy variable (LSDV) approach.
} 
The dependent variable is defined as follows:

$$
\text { Litter }_{i t}=\frac{s_{i t}}{c_{i t}}
$$

where $s_{i t}$ is the number of cigarette butts dropped in the sand of the beach resort $i$ on day $t$ and $c_{i t}$ is the number of customers ${ }^{21}$ who visited the same beach resort $i$ on day $t$. The choice of the "per capita" number of cigarettes discarded in the sand allows us to account for between-day or between-beach resort variations in visitor attendance. As we explain in what follows, in a second model specification, the number of per capita cigarette butts is specified at the week rather than the day level, in order to reduce potential daily variability.

To check the robustness of the treatments, we use as alternative dependent variable the ratio of the number of cigarette butts collected from the sand and the overall number of cigarettes butts found at each beach resort, corresponding to the sum of the filters in the sand and in trash bins or portable ashtrays. Formally:

$$
\text { Litter }_{i t}=\frac{s_{i t}}{n_{i t}+s_{i t}},
$$

where $n_{i t}$ is the number of cigarette ends collected from the portable ashtrays and generic bins in beach resort $i$ on day $t$. This variable, which can be interpreted as a measure of the "incidence" of butts improperly disposed of over the total number of cigarettes discarded, properly and improperly, allows us to take account of potentially different smoking habits of customers in different beach resorts.

ASHTRAYS and ASHTRAYS PLUS MESSAGE are two dummy variables taking the value 1 if beach resorts are in the respective treatment group and 0 otherwise. $X_{i t}$ is a vector of time-variant beach resorts' characteristics, including the number of covers at the restaurant or bar in each resort ( Restaurant $_{i t}$ ), and a dummy variable for special events taking place at the resort $\left(\right.$ Events $\left._{i t}\right)$ in order to account for the attractiveness of beach resorts and the potential increase of cigarette waste due to particular activities or events. Furthermore, we include the average rental prices of holiday flats within a $1 \mathrm{~km}$ distance from each beach resort $\left(\right.$ Rentalprice $\left._{i t}\right)$. We extracted data from a large real estate platform in Italy, Immobiliare.it. The data were updated weekly, on Mondays, during the 53 days of the experiment. This variable captures the socio-economic conditions of customers, reflecting their disposable income, keeping distance constant. According to the dependent variable adopted in different specifications, we include also the number of cigarette butts collected from ashtrays/ bins, or the number of customers as additional controls.

$Z_{i}$ includes beach resort characteristics which are constant over time, i.e. the number of sunshades $\left(\right.$ Shade $\left._{\mathrm{i}}\right)$ and the overall area $\left(\right.$ Area $\left._{i}\right)$.

In order to consider short-term trends, we include both day fixed effects and day-of-the-week fixed effects. The latter is intended to capture habitual trends, such

\footnotetext{
21 The number of customers was provided by beach resort managers, based on the number of deckchairs rented by the visitors, a necessary requirement to remain on the beach.
} 
as, for instance, higher customer attendance on specific days due to organizational agreements of beach resorts with local hotels, as well as the presence of occasional smokers during weekends.

We perform some sensitivity analyses by including climatic variables (summarized by the variable Weather ${ }_{t}$ in Eq. 1), since the number of visitors, the length of their daily stay at beach resorts, and therefore the number of cigarettes smoked may be influenced by weather conditions. ${ }^{22}$ Specifically, we consider the daily mean temperature $\left(\right.$ Temp $\left._{t}\right)$, the daily average solar radiation intensity $\left(\right.$ Sun $\left._{t}\right)$, and the daily average wind speed $\left(\right.$ Wind $_{t}$ ), between 7 am and 7 pm (respective opening and closing times of the beaches). Wind speed is included in the regressions since it can affect the movement of floating butts; moreover, if the wind is particularly strong, local regulations force resort managers to close sunshades, thereby reducing attendance. We gathered data from the Environmental Agency in Emilia-Romagna (ARPA - Emilia Romagna), which collects and publishes hourly climatic data. Our data come from the weather stations of Cesena and Cesenatico Porto, located near the beach resorts involved, the former reporting the average daily solar radiation, the latter the daily mean temperature and wind speed.

Figure 1 provides the pattern of the number of filters per capita over time. As the figure shows, the pattern is quite regular in the three groups and it does not display any particular trend during weekends, when occasional customers are more likely to visit the beach resorts.

Summary statistics for the dependent variables and beach resort characteristics are provided in Table 1; Table 2 presents summary statistics per treatment group for Litter and Litter2 and their components.

To test for the existence of potential imbalances in beach resort characteristics across the three groups, we report the results of a regression testing for significant differences, following the approach in Altmann and Traxler (2014). Table 3 shows the average values and standard deviations for relevant beach resort characteristics ${ }^{23}$ by treatment group, and the respective p-values of the F-test and t-test. Results suggest that, at most with the possible exception for the low statistical significance of the variable "Events", resort characteristics are reasonably balanced between treatments and control.

As suggested by Fig. 1 and confirmed by the box-plot in Fig. 6 (in the Appendix), the dependent variables Litter and Litter 2 contain some outliers, including observations above $60 \%$, which represent $3 \%$ of the total sample. To check whether they bias the significance of the treatments, in Table 5 in the Appendix we show regression results by excluding outliers from the analysis.

\footnotetext{
22 When we include climatic variables, day fixed effect are excluded from the empirical model.

23 We cannot provide t-test results for the variables fixed at beach level, however these are quite similar across treatment groups (average values for Area: ASHTRAYS 3870; ASHTRAYS PLUS MESSAGE 3887.7; CONTROL 3757.5; average values for Shade: ASHTRAYS 158.66; ASHTRAYS PLUS MESSAGE 149; CONTROL 166.5).
} 


\section{Econometric results}

Preliminary, we perform t-tests for the equivalency of mean respectively between ASHTRAYS and ASHTRAYS PLUS MESSAGE with respect to the CONTROL group (i.e. $H_{0}=\bar{X}_{\text {TREATED }}=\bar{X}_{\text {UNTREATED }}$ ). Specifically, we find that, for the variable Litter (the ratio of the number of cigarette ends in the sand and the number of customers), the difference in means between ASHTRAYS and CONTROL is highly statistically significant $(\mathrm{t}=-2.911 ; \mathrm{p}<0.001)$ and weakly significant for ASHTRAYS PLUS MESSAGE $(t=-1.599 ; \mathrm{p}<0.05)$. For Litter 2 (the ratio of cigarette butts in the sand and the overall number of cigarettes butts), the difference in means is highly statistically significant both between ASHTRAYS and CONTROL and ASHTRAYS PLUS MESSAGE and CONTROL $(\mathrm{t}=-5.420$ and $\mathrm{t}=-6.603 ; \mathrm{p}<0.001$ level $)$.

Nevertheless, as noted by List (2011), since the significance of the treatment effects may be the result of variables left uncontrolled, we supplement the results of the statistical tests with the estimates resulting from running regressions of Eq. 1 for both dependent variables.

Table 4 reports the estimation results. The first two rows show that both treatments are statistically significant compared to the control group under different model specifications. Standard errors are clustered at the beach-week level to account for potential customer turnover. When we use the daily number of per capita cigarette ends found into the sand (Litter, defined in eq. 2) as the dependent variable, treatment ASHTRAYS provides a reduction in a range from -10 to $-12 \%$, while the ASHTRAYS PLUS MESSAGE treatment corresponds to a reduction from -7 to $-10 \%$, depending on the control variables included in the model (Columns 1 and 5-7 which include weather variables).

Column 2 estimates the model using Litter as the dependent variable, calculated at the weekly rather than the daily level to exclude potential biases due to lower attendance on some days or at some beach resorts, which could overestimate the effect of the interventions. Treatments continue to be significant for reducing cigarette butt littering even when this smoother outcome variable is adopted.

Column 3 in Table 4 shows that also the incidence of butts in the sand (measured by the variable Litter2, defined in Eq. 3) is significantly reduced by the treatments, corresponding to $-10 \%$ and $-13.6 \%$ for treatment ASHTRAYS and treatment ASHTRAYS PLUS MESSAGE, respectively.

Column 4 excludes from the analysis the first quartile of Litter (with values roughly up to $12 \%$ of the sample), in order to avoid potential measurement errors. Both treatments continue to have a statistically significant effect on reducing the ratio of cigarette ends thrown onto the sand although the significance is stronger for the treatment ASHTRAYS.

As it is shown by Table 5 in the Appendix, the significance of the treatments is confirmed also when we exclude from the analysis potential outliers (values above $60 \%$ of the observations). Even though the value of the coefficients is slightly lower, the bulk of the results is not affected by extreme values. 
Fig. 1 Evolution of the average number of per capita cigarette butts overtime. Week-ends specified in shadowed areas

Table 1 Summary statistics of dependent and explanatory variables (total sample)

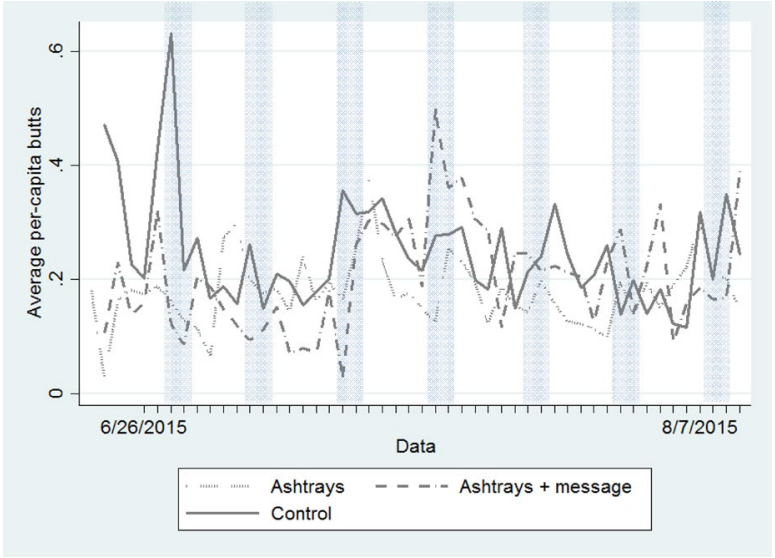

Note: Week - ends specified in shadowed areas.

\begin{tabular}{lrrll}
\hline Variable & \multicolumn{1}{c}{ Mean } & \multicolumn{1}{l}{ SD } & Min & Max \\
\hline Litter & 0.21 & 0.17 & 0.01 & 1.16 \\
Litter2 & 0.23 & 0.15 & 0.01 & 0.88 \\
Butts in sand & 26.16 & 22.53 & 1 & 158 \\
Butts in ashtrays/bins & 95.70 & 70.52 & 3 & 470 \\
Customers & 134.82 & 65.70 & 35 & 260 \\
Rental price & 15.02 & 9.44 & 9.58 & 57.63 \\
Restaurant & 114.98 & 53.29 & 57 & 270 \\
Shade & 164.87 & 66.35 & 90 & 260 \\
Area & 3848.5 & 1333.45 & 1800 & 5330 \\
Events & 0.072 & 0.26 & 0 & 1 \\
Temp & 25.45 & 2.76 & 19.48 & 29.1 \\
Sun & 534.62 & 83.28 & 262.95 & 634.25 \\
Wind & 3.61 & 0.75 & 1.81 & 5.13 \\
\hline
\end{tabular}

Litter is defined as the number of cigarette butts collected in the sand (Butts in sand) per customer in each day (see Eq. 2); Litter2 is the ratio between the number of cigarette ends collected in the sand and the total number of cigarette ends (Butts in sand + Butts in ashtrays/ bins) collected in each day (see Eq. 3). Customers is the daily number of visitors in each beach resort. Rental price (average rental price of holiday flats within a distance of $1 \mathrm{~km}$ from each beach resort), Restaurant (the number of covers at the restaurant/bar beach resort), and Events (special events in the beach resort) change across time, while Shade (number of sunshades in the resort) and Area (area of the beach resort) are constant. Meteorological variables (Temp, Sun and Wind) are updated daily and measured respectively in degree Celsius, Watt/sqm and $\mathrm{m} / \mathrm{s}$

Overall, we can conclude that the findings support our first research hypothesis: portable ashtrays, which increase the convenience of a proper disposal, reduce cigarette waste in the sand. 
Table 2 Summary statistics of dependent variables and their main components, per treatment group and daily level

\begin{tabular}{lrrll}
\hline Variable & Mean & SD & Min & Max \\
\hline Control & & & & \\
Litter & 0.24 & 0.20 & 0.25 & 1.16 \\
Litter2 & 0.32 & 0.16 & 0.05 & 0.88 \\
Butts in sand & 25.81 & 12.96 & 6 & 87 \\
Butts in ashtrays/bins & 79.05 & 77.99 & 6 & 470 \\
Customers & 157.64 & 80.34 & 70 & 260 \\
Ashtrays & & & & \\
Litter & 0.18 & 0.11 & 0.02 & 0.71 \\
Litter2 & 0.21 & 0.13 & 0.01 & 0.78 \\
Butts in sand & 23.51 & 15.90 & 1 & 81 \\
Butts in ashtrays/bins & 96.20 & 57.16 & 3 & 375 \\
Customers & 132.69 & 68.46 & 35 & 250 \\
Ashtrays Plus Message & & & & \\
Litter & 0.20 & 0.18 & 0.01 & 0.85 \\
Litter2 & 0.19 & 0.13 & 0.02 & 0.61 \\
Butts in sand & 29.12 & 31.82 & 1 & 158 \\
Butts in ashtrays/bins & 106.63 & 74.96 & 13 & 414 \\
Customers & 121.73 & 45.34 & 50 & 220 \\
\hline
\end{tabular}

Litter is defined as the number of cigarette butts collected in the sand per customer in each day (see Eq. 2); Litter2 is the ratio between the number of cigarette ends collected in the sand and the total number of cigarette ends collected in each day (see Eq. 3). Customers is the daily number of visitors in each beach resort

Table 3 Comparison of resorts' characteristics between treated and control groups

\begin{tabular}{lccccc}
\hline & Control & Ashtrays & $\begin{array}{l}\text { Ashtrays plus mes- } \\
\text { sage }\end{array}$ & F-test (p-values) & t-test (p-values) \\
\hline Rental price & $12.14(3.53)$ & $20.35(13.53)$ & $11.61(1.11)$ & 0.496 & 0.407 \\
Restaurant & $142(58.28)$ & $119.94(60.66)$ & $92(24.91)$ & 0.497 & 0.476 \\
Events & $0.173(0.38)$ & $0.058(0.23)$ & $0.019(0.13)$ & 0.109 & 0.066 \\
Customers & $157.64(80.34)$ & $132.68(68.45)$ & $121.73(45.33)$ & 0.853 & 0.649
\end{tabular}

Mean values (standard deviations in parentheses). The final two columns report (i) p-values of F-tests from regressions of the respective characteristic on treatment dummies and (ii) p-values of t-tests comparing the characteristic in the control group vs all treated resorts. Events is estimated through probit regression (Wald chi2 value is reported)

For all the model specifications in Table 4, the difference between the coefficients of the two treatments is not statistically significant, as shown by the Fischer test results presented at the bottom of Table 4. This suggests that, in the present 


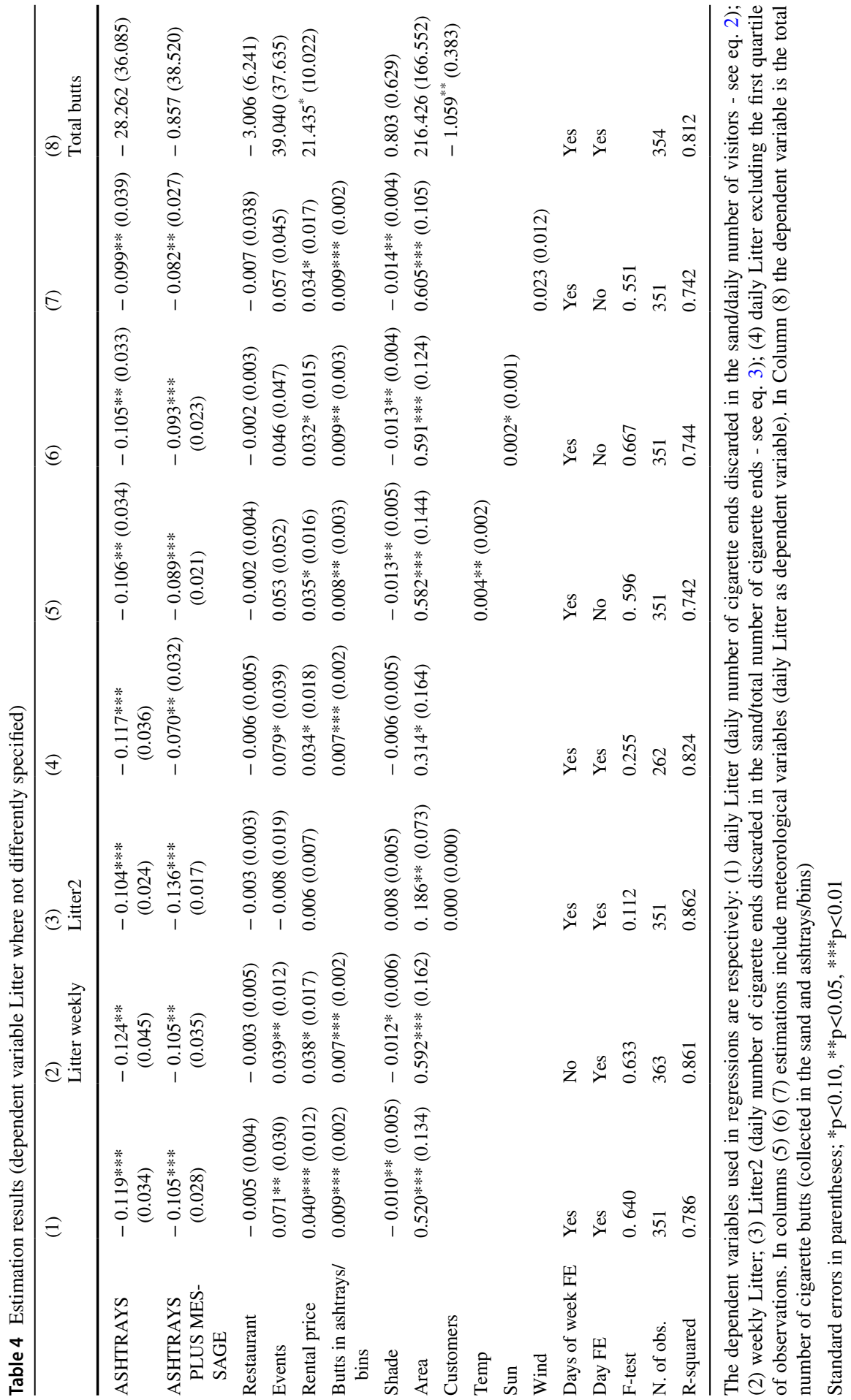




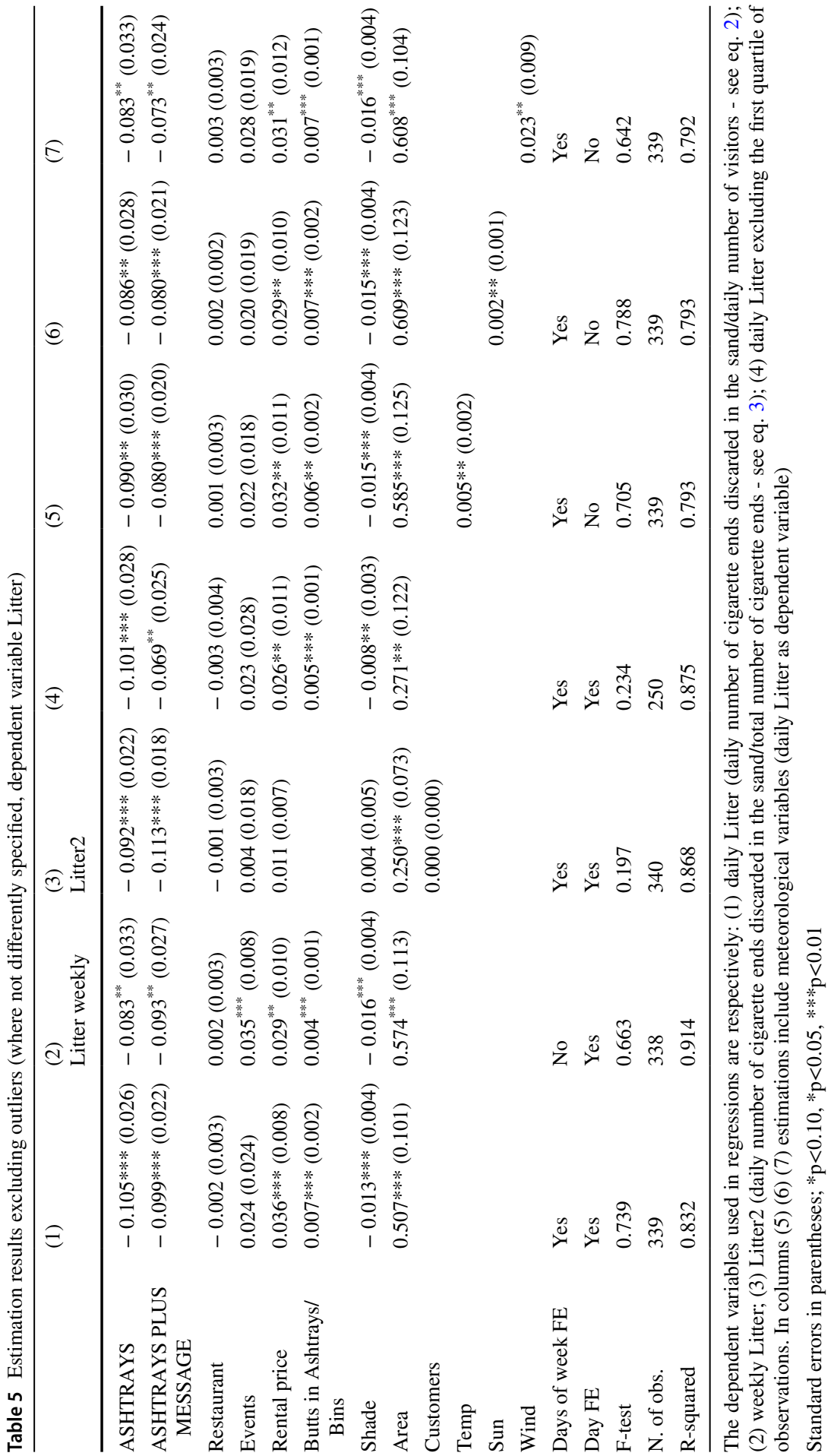


case-study, the two treatments have a similar effect on reducing improper butt disposal behavior. ${ }^{24}$ In contrast to our expectations related to the second research hypothesis, reinforcing the effect of the ashtrays with a social message provides no additional effect. Specifically, in our setting we cannot identify either a crowding out or a crowding in effect of the message compared to the simple availability of free portable ashtrays.

Finally, to account for potentially unwanted side-effects induced by treatments in terms of smoking incentives, we consider the total number of cigarette filters collected as the dependent variable. This allows us to evaluate whether the introduction of portable ashtrays and the social cue affected customers' smoking habits. The results are presented in Column 8 in Table 4 . It can be seen that none of the treatments seems to have affected the total number of cigarette ends collected (and hence "smoked") at beach resorts.

\section{Discussion and concluding remarks}

Our field experiment shows that the availability of portable ashtrays which makes proper butt disposal "less costly" has a substantial effect on reducing littering. On the other hand, accompanying ashtrays with a message encouraging proper disposal does not appear to induce a statistically significant additional effect on pro-environmental behavior compared to the first treatment.

Our findings suggest that the effort cost of proper disposal is the main driver behind cigarette end littering behavior, and that the impact of an intervention aimed at reducing this cost seems to be of first-order importance compared to the impact of a behavioral incentive. According to our experiment, therefore, cigarette butt littering is another example supporting the idea that behavioral tools should be used to complement rather than substitute policies grounded in conventional economics (Loewenstein et al. 2012).

Although some caution is advised when interpreting our results since they are based on a small sample of beach resorts, the current case study offers some suggestions about the drivers of cigarette butt littering, and contributes to the policy debate on the issue by providing further empirical evidence. Specifically, the experimental results and the subsequent decision of local authorities to mandate the use of mobile receptacles in beach resorts to reduce cigarette littering highlight the importance of investigating the main drivers behind improper environmental behaviors, in order to correct them. Policy interventions and environmental policies, in particular, should be designed by taking into account individual motivations and the different role that economic and non-economic incentives may play in affecting people's behaviors.

In our specific case, even though the limited impact of the message is in line with previous studies investigating the effect of prompts on littering behavior (Finnie 1973; Sibley and Liu 2003), it may also be the consequence of the text we adopted to activate a social norm. In particular, by encouraging people to make an effort to

${ }^{24}$ This result s confirmed also when we exclude outliers (Table 5 in the Appendix). 
preserve the cleanliness of their beach, the message was intended to encourage a sense of community pride in each resort. Nevertheless, to be effective in changing behavior, it is likely that this kind of norm needs to be internalized by individuals (Mols et al. 2015), which would require a much longer period compared to the timespan of the experiment. A further extension of the work could entail the use of different messages. Given the context we have considered, the display of notices on the risks of marine creatures ingesting butts might provide interesting insights, especially if combined with a prompt based on "social proof" that referent others are changing their behavior. Indeed, social comparative feedback can stimulate pro-environmental behaviors because individuals tend to be more inclined to choose appropriate actions if they perceive others to be complying with them, as shown by recent research on recycling (Schultz 1999; Dupré and Meineri 2016), reduction of bottled water consumption (van der Linden 2015), and public littering (Cialdini et al. 1990).

The particular "environment" of our experiment is interesting because of its characteristics. On the one hand, during the summer, people spend several hours in the same spot sunbathing. While it is extremely easy and effortless to discard (and hide) a cigarette butt in the sand after smoking, proper disposal can be inconvenient since it requires the individual to get up from the beach and walk to find an ashtray. In the involved resorts, central trash bins (in a number between 6 and 8 depending on the size of the resort) are located near the runway to enter the beach and near the coffee shop/restaurant. This implies that, in order to reach the ashtray, smokers have to walk on the sand even few minutes to reach the bin (according to the distance of their deckchairs from the bins), an action which can be unpleasant especially in the hottest part of the day. Therefore, this context is ideal to evaluate the cost-reduction effect of portable ashtrays which can be placed on the sand near the beach deckchair, or carried around. At the same time, studying people who spend the day in the same place allows us to observe the effect of our interventions on passive littering, which, as underlined by Sibley and Liu (2003) is more resistant to change than active littering, and less likely to entail negative social consequences since it is less overt.

Funding Open access funding provided by Università degli Studi di Roma Tor Vergata within the CRUICARE Agreement.

Open Access This article is licensed under a Creative Commons Attribution 4.0 International License, which permits use, sharing, adaptation, distribution and reproduction in any medium or format, as long as you give appropriate credit to the original author(s) and the source, provide a link to the Creative Commons licence, and indicate if changes were made. The images or other third party material in this article are included in the article's Creative Commons licence, unless indicated otherwise in a credit line to the material. If material is not included in the article's Creative Commons licence and your intended use is not permitted by statutory regulation or exceeds the permitted use, you will need to obtain permission directly from the copyright holder. To view a copy of this licence, visit http://creativecommons.org/licen ses/by/4.0/.

\section{Appendix}

See Figs. 2, 3, 4, 5, 6 and Table 5. 

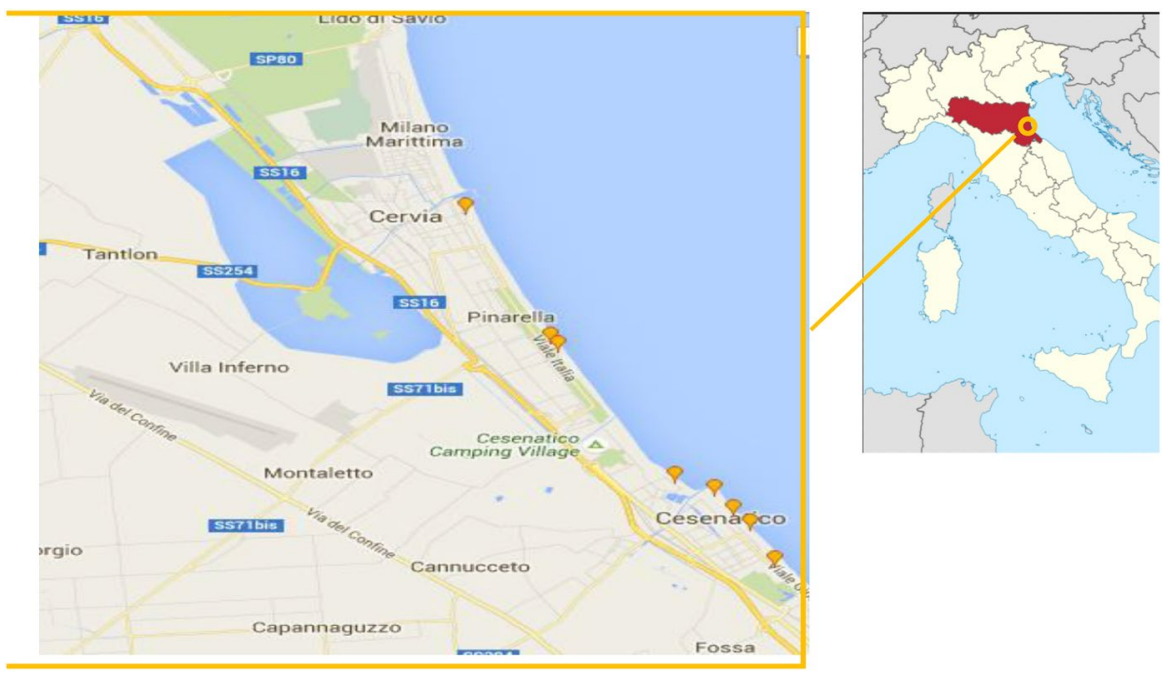

Fig. 2 Location of beach resorts involved in the experiment

Fig. 3 An example of portable ashtrays location

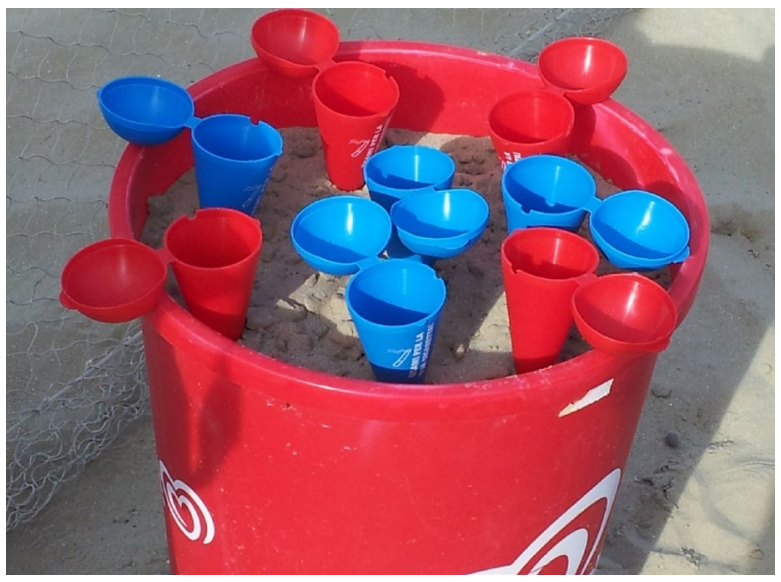




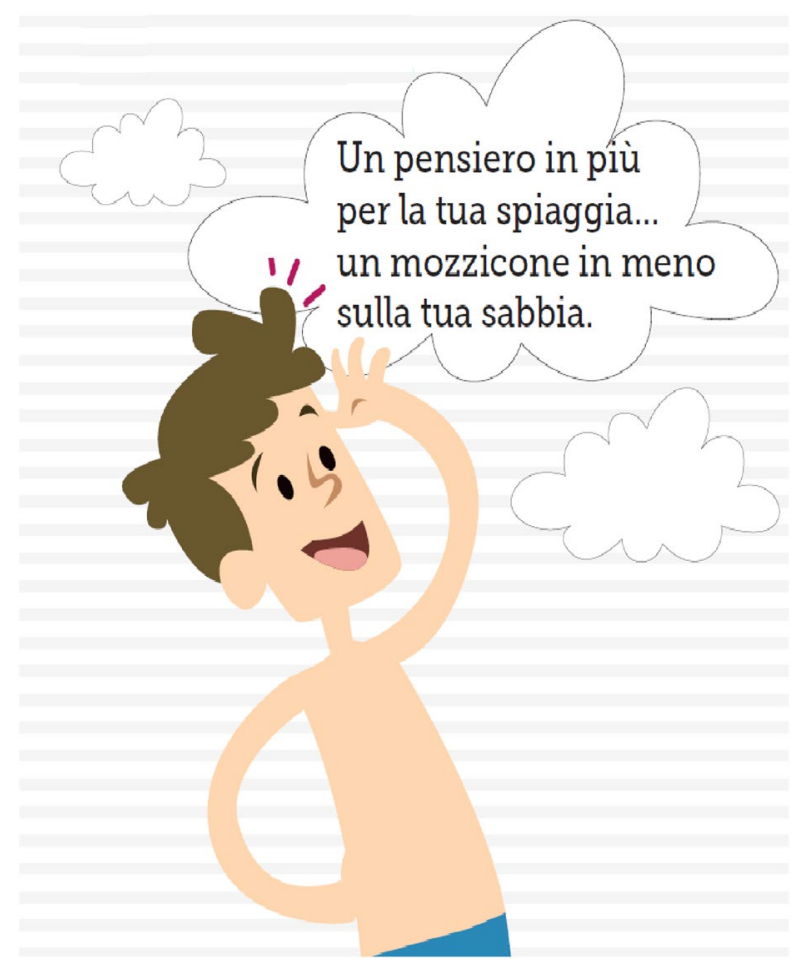

Fig. 4 The message (in Italian)

Fig. 5 The collection process

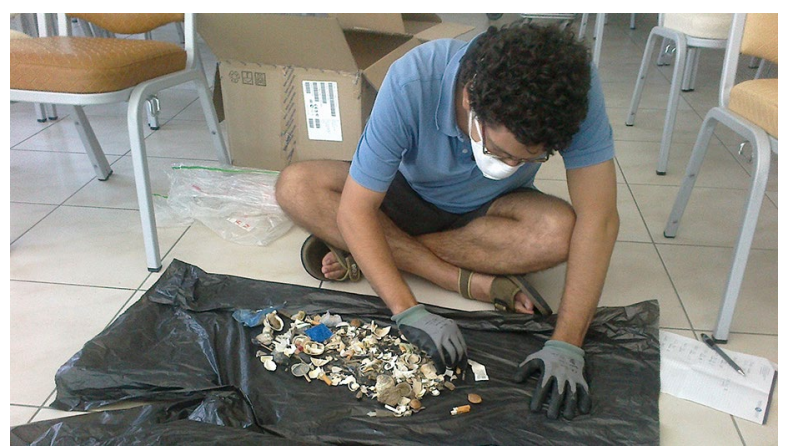


Fig. 6 Box plot of the per capita cigarette butts by treatment group

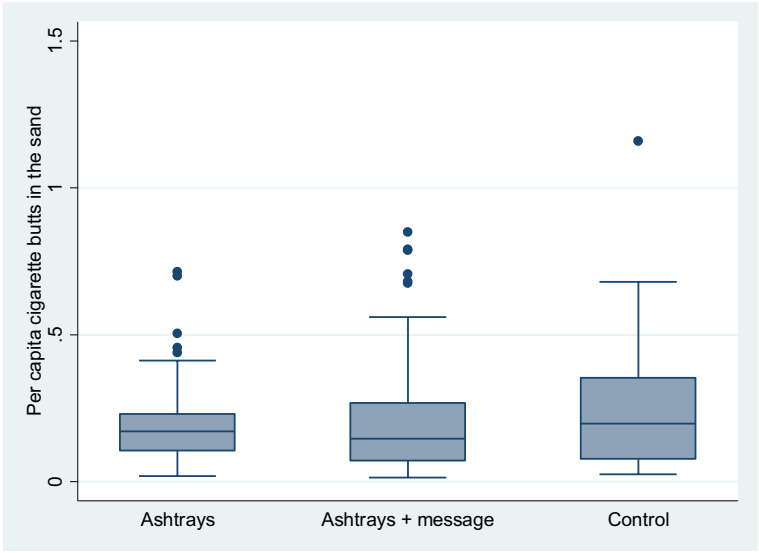

\section{References}

Altmann, S., \& Traxler, C. (2014). Nudges at the dentist. European Economic Review, 72, 19-38.

Barnes, R. L. (2011). Regulating the disposal of cigarette butts as toxic hazardous waste. Tobacco Control, 20 (Suppl 1), i45-i48.

Bell, J., Huber, J., \& Viscusi, W. K. (2017). Fostering recycling participation in Wisconsin households through single-stream programs. Land Economics, 93(3), 481-502.

Bonanomi, G., Incerti, G., Cesarano, G., Gaglione, S. A., \& Lanzotti, V. (2015). Cigarette butt decomposition and associated chemical changes assessed by 13C CPMAS NMR. PLoS One, 10(1), e0117393.

Burgess, R. L., Clark, R. N., \& Hendee, J. C. (1971). An experimental analysis of anti-litter procedures. Journal of Applied Behavior Analysis, 4(2), 71-75.

Centers for Disease Control and Prevention-CDC. (1997). Ingestion of Cigarettes and Cigarette Butts by Children-Rhode Island, January 1994-July 1996, 46(06). Morbidity and Mortality Weekly Report, 46(6), 125-128.

Charness, G., Gneezy, U., \& Kuhn, M. A. (2012). Experimental methods: between-subject and withinsubject design. Journal of Economic Behavior and Organization, 81(1), 1-8.

Chetty, R. (2015). Behavioral economics and public policy: A pragmatic perspective. The American Economic Review, 105(5), 1-33.

Choe, C., \& Fraser, I. (1998). The economics of household waste management: A review. The Australian Journal of Agricultural and Resource Economics, 42(3), 269-302.

Cialdini, R. B. (2003). Crafting normative messages to protect the environment. Current Directions in Psychological Science, 12(4), 105-109.

Cialdini, R. B., Reno, R. R., \& Kallgren, C. A. (1990). A focus theory of normative conduct: Recycling the concept of norms to reduce littering in public places. Journal of Personality and Social Psychology, 58(6), 1015-1026.

Cope, G. J., Huffmann, K. T., Allred, L. J., \& Grossnickle, W. F. (1993). Behavioral strategies to reduce cigarette litter. Journal of Social Behavior and Personality, 8, 607-619.

Curtis, C., Collins, S., Cunningham, S., Stigler, P., \& Novotny, T. E. (2014). Extended producer responsibility and product stewardship for tobacco product waste. International Journal of Waste Resources, 4(3), 1-19.

Dupré, M., \& Meineri, S. (2016). Increasing recycling through displaying feedback and social comparative feedback. Journal of Environmental Psychology, 48, 101-107.

De Kort, Y. A., McCalley, L. T., \& Midden, C. J. (2008). Persuasive trash cans: Activation of littering norms by design. Environment and Behavior, 40(6), 870-891.

Derraik, J. G. (2002). The pollution of the marine environment by plastic debris: A review. Marine Pollution Bulletin, 44, 842-852. 
Dobaradaran, S., Schmidt, T. C., Nabipour, I., Ostovar, A., Raeisi, A., Saeedi, R., et al. (2018). Cigarette butts abundance and association of mercury and lead along the Persian Gulf beach: An initial investigation. Environmental Science and Pollution Research, 25(6), 5465-5473.

Dobbs, I. M. (1991). Litter and waste management: Disposal taxes versus user charges. Canadian Journal of Economics, 24(1), 221-227.

Dur, R., \& Vollaard, B. (2015). The power of a bad example: A field experiment in household garbage disposal. Environment and Behavior, 47(9), 970-1000.

Ferrara, I. (2008). Waste generation and recycling. OECD Journal: General Papers, 2, 19-58.

Finnie, W. C. (1973). Field experiments in litter control. Environment and Behavior, 5(2), 123-144.

Geller, E. S., Brasted, W. S., \& Mann, M. F. (1979). Waste receptacle designs as interventions for litter control. Journal of Environmental Systems, 9(2), 145-160.

Green, D. S., Boots, B., Carvalho, J. D. S., \& Starkey, T. (2019). Cigarette butts have adverse effects on initial growth of perennial ryegrass (gramineae: Lolium perenne L.) and white clover (leguminosae: Trifolium repens L.). Ecotoxicology and Environmental Safety, 182, 109418.

Green, A. L. R., Putschew, A., \& Nehls, T. (2014). Littered cigarette butts as a source of nicotine in urban waters. Journal of Hydrology, 519, 3466-3474.

Halvorsen, B. (2008). Effects of norms and opportunity cost of time on household recycling. Land Economics, 84(3), 501-516.

Hansmann, R., Loukopoulos, P., \& Scholz, R. W. (2009). Characteristics of effective battery recycling slogans: A Swiss field study. Resources Conservation Recycling, 53, 218-230.

Healton, C. G., Cummings, K. M., O'connor, R. J., \& Novotny, T. E. (2011). Butt really? The environmental impact of cigarettes. Tobacco Control, 20(Suppl 1), i1-i1.

Kallgren, C. A., Reno, R. R., \& Cialdini, R. B. (2000). A focus theory of normative conduct: When norms do and do not affect behavior. Personality and Social Psychology Bulletin, 26(8), 1002-1012.

Kinnaman, T. C., \& Fullerton, D. (1999). The economics of residential solid waste management, No. w7326, National Bureau of Economic Research.

Kurz, V. (2018). Nudging to reduce meat consumption: Immediate and persistent effects of an intervention at a university restaurant. Journal of Environmental Economics and Management, 90, 317-341.

Levitt, S. D., \& List, J. A. (2009). Field experiments in economics: The past, the present, and the future. European Economic Review, 53(1), 1-18.

List, J. A. (2011). Why economists should conduct field experiments and 14 tips for pulling one off. Journal of Economic Perspectives, 25(3), 3-16.

Lombardi, C. C., Di Cicco, G., \& Zagà, V. (2009). Le cicche di sigaretta: Un rifiuto tossico dimenticato (The cigarette butts: A forgotten toxic waste). Tabaccologia, 4, 27-36.

Loewenstein, G., Asch, D. A., Friedman, J. Y., Melichar, L. A., \& Volpp, K. G. (2012). Can behavioural economics make us healthier. BMJ, 344(7863), 23-25.

Loizidou, X. I., Loizides, M. I., \& Orthodoxou, D. L. (2018). Persistent marine litter: Small plastics and cigarette butts remain on beaches after organized beach cleanups. Environmental Monitoring and Assessment, 190(7), 414.

Mcgregor Marketing, Rothmans of Pall Mall Australia, N403 (1998), Please bin your butts research on cigarette littering, Stage 3-Smoker Survey Project No: 4290, Philip Morris Records. Retrieved from: https://www.industrydocumentslibrary.ucsf.edu/tobacco/docs/yffy0090.

Malizia, E., Andreucci, G., Alfani, F., Smeriglio, M., \& Nicholai, P. (1983). Acute intoxication with nicotine alkaloids and cannabinoids in children from ingestion of cigarettes. Human Toxicology, 2, 315-316.

Moerman, J. W., \& Potts, G. E. (2011). Analysis of metals leached from smoked cigarette litter. Tobacco Control, 20(1), i30-i35.

Mols, F., Haslam, A., Jetten, J., \& Steffens, N. K. (2015). Why a nudge is not enough: A social identity critique of governance by stealth. European Journal of Political Research, 54, 81-98.

Munari, C., Corbau, C., Simeoni, U., \& Mistri, M. (2016). Marine litter on Mediterranean shores: Analysis of composition, spatial distribution and sources in north-western Adriatic beaches. Waste Management, 49, 483-490.

Novotny, T. E., \& Slaughter, E. (2014). Tobacco product waste: an environmental approach to reduce tobacco consumption. Current environmental health reports, 1(3), 208-216.

Novotny, T. E., Hardin, S. N., Hovda, L. R., Novotny, D. J., McLean, M. K., \& Khan, S. (2011). Tobacco and cigarette butt consumption in humans and animals. Tobacco Control, 20(Suppl 1), i17-i20. 
Novotny, T. E., Lum, K., Smith, E., Wang, V., \& Barnes, R. (2009). Cigarettes butts and the case for an environmental policy on hazardous cigarette waste. International Journal of Environmental Research and Public Health, 6(5), 1691-1705.

Conservancy, Ocean. (2019). International coastal cleanup 2018 report: To the beach and beyond. Washington, DC, USA: Ocean Conservancy.

O’Neill, G. W., Blanck, L. S., \& Joyner, M. A. (1980). The use of stimulus control over littering in a natural setting. Journal of Applied Behavior Analysis, 13(2), 379-381.

Ong, I. B. L., \& Sovacool, B. K. (2012). A comparative study of littering and waste in Singapore and Japan. Resources, Conservation and Recycling, 61, 35-42.

Poeta, G., Battisti, C., \& Acosta, A. T. (2014). Marine litter in Mediterranean sandy littorals: Spatial distribution patterns along central Italy coastal dunes. Marine Pollution Bulletin, 89(1-2), 168-173.

Rath, J. M., Rubenstein, R. A., Curry, L. E., Shank, S. E., \& Cartwright, J. C. (2012). Cigarette Litter: Smokers' Attitudes and Behaviors. International journal of environmental research and public health, 9, 2189-2203.

Reich, J. W., \& Robertson, J. L. (1979). Reactance and norm appeal in anti-littering messages. Journal of Applied Social Psychology, 9(1), 91-101.

Reiter, S. M., \& Samuel, W. (1980). Littering as a function of prior litter and the presence or absence of prohibitive signs. Journal of Applied Social Psychology, 10(1), 45-55.

Roales-Nieto, J. G. (1988). A behavioral community program for litter control. Journal of community Psychology, 16(2), 107-118.

Rochman, C. M., Hoh, E., Kurobe, T., \& Teh, S. J. (2013). Ingested plastic transfers hazardous chemicals to fish and induces hepatic stress. Scientific Reports, 3, 3263.

Rochman, C. M., Tahir, A., Williams, S. L., Baxa, D. V., Lam, R., Miller, J. T., et al. (2015). Anthropogenic debris in seafood: Plastic debris and fibers from textiles in fish and bivalves sold for human consumption. Scientific reports, 5, 14340.

Schneider, J. E., Peterson, N. A., Kiss, N., Ebeid, O., \& Doyle, A. S. (2011). Tobacco litter costs and public policy: A framework and methodology for considering the use of fees to o set abatement costs. Tobacco control, 20 (Suppl 1), i36-i41.

Schultz, P. W. (1999). Changing behavior with normative feedback interventions: A field experiment on curbside recycling. Basic and Applied Social Psychology, 21(1), 25-36.

Schultz, P. W., Bator, R. J., Large, L. B., Bruni, C. M., \& Tabanico, J. J. (2013). Littering in context: Personal and environmental predictors of littering behavior. Environment and Behavior, 45(1), 35-59.

Sibley, C. G., \& Liu, J. H. (2003). Differentiating active and passive littering a two-stage process model of littering behavior in public spaces. Environment and Behavior, 35(3), 415-433.

Slaughter, E., Gersberg, R., Watanabe, K., et al. (2011). Toxicity of cigarette butts, and their chemical components, to marine and freshwater fish. Tobacco Control, 20, i25-i29.

Smith, E. A., \& Novotny, T. E. (2011). Whose butt is it? Tobacco industry research about smokers and cigarette butt waste. Tobacco Control, 20(Suppl 1), i2-i9.

Strafella, P., Fabi, G., Despalatovic, M., Cvitković, I., Fortibuoni, T., Gomiero, A., et al. (2019). Assessment of seabed litter in the Northern and Central Adriatic Sea (Mediterranean) over six years. Marine Pollution Bulletin, 141, 24-35.

UNEP. (2009). Marine litter: A global challenge. Nairobi: UNEP.

Van Cauwenberghe, L., \& Janssen, C. R. (2014). Microplastics in bivalves cultured for human consumption. Environmental Pollution, 193, 65-70.

Van Der Linden, S. (2015). Exploring beliefs about bottled water and intentions to reduce consumption: The dual-effect of social norm activation and persuasive information. Environment and Behavior, 47(5), 526-550.

Wilcox, C., Mallos, N. J., Leonard, G. H., Rodriguez, A., \& Hardesty, B. D. (2016). Using expert elicitation to estimate the impacts of plastic pollution on marine wildlife. Marine Policy, 65, 107-114.

Wright, S. L., Rowe, D., Reid, M. J., Thomas, K. V., \& Galloway, T. S. (2015). Bioaccumulation and biological effects of cigarette litter in marine worms. Scientific Reports, 5(1), 1-10.

Publisher's Note Springer Nature remains neutral with regard to jurisdictional claims in published maps and institutional affiliations. 